\title{
A STUDY ON THE SIGNIFICANCE OF MOTIVATIONAL CLASSROOM STRATEGIES AS CONCEIVED BY SCIENCE TEACHERS AT SECONDARY LEVEL
}

\author{
Khalid Khurshid* \\ Shazia Noureen** \\ Shamim Haider Tirmazi***
}

\begin{abstract}
The present study was conducted to investigate teachers' use of classroom motivational strategies during their teaching to secondary school science classes. Motivational strategies are always helpful for the teachers in the classroom to achieve their goals. The main objective of the study was to determine the motivational classroom strategies used by secondary school science teachers during their science lessons. The study was limited to collect data from secondary school science teachers who were teaching to grade $9^{\text {th }}$ and $10^{\text {th }}$ science students. The study was descriptive and a questionnaire comprising 25 closed ended statements was developed on 5 point Likert type scale to collect the data from 256 secondary school science teachers teaching science subjects in secondary schools of two districts of Multan division; Multan and district Vehari. The results of present study showed that teacher motivation is related to teachers' use of motivating strategies, which in turn are related to student motivation. It was also noticed that English medium school teachers use these strategies more frequently as compared to Urdu medium schools teachers. Gender wise analysis also revealed that male teachers are more frequent and enthusiastic to use motivational strategies in their science classroom as compared to female science teachers.
\end{abstract}

Key words: significance, motivational, strategies, secondary school, science teachers.

\footnotetext{
*Assistant Professor, Department of Education, BZU, Multan.

**Visiting Faculty, Department of Education, BZU, Multan.

***Associate Professor, Department of Education, BZU, Multan.
} 


\section{Introduction}

Motivation is an important aspect of teaching and learning process (Odera, 2011). Teaching of science at every level requires some strategies to motivate students for learning the subject with interest and concentration. If a new science teacher prepares a well sequenced plan for his lesson and presents in a good way still fails to deliver the concepts, and ultimately the students become bore and unsatisfied due to static learning. Nbina (2011, p.414) noted that "most of the time science teaching remains a telling instruction rather than doing". It is a common observation that senior science teachers are well aware of techniques used to teach science subjects effectively. One of the study carried out by Mellado, et al (2007, p.3) indicated that experienced teachers are more concerned about the classroom practices than novice teachers. Mary (2010, p.1) quoted Analoui (2000) that "the motivation guides students towards achievement of their goals".

In a survey of 400 secondary school students from eight different schools in Pakistan, Atta and Jamil (2012, pp. 427-431) found that there was a significant and positive effect of motivation and parental influence on the educational attainments of the students at secondary level. The educational attainment of those students who were under the influence of their parents and were motivated was found to be better.

Pickens (2007, p.3) believed that the teaching of science in high school often involved lecture method, note-taking, and mostly rely on working from the textbook; all of which results in student disengagement. As results, high school students often perceive the subject of science as boring, hard or difficult, and irrelevant to their everyday lives. So, in this situation motivational strategies can play a vital role to engage student's to take active part during their science lessons. In view of Pickens (2007), most of the research studies clearly indicated that motivating adolescents was not an easy job. Furthermore, Evans (2004) and Theobald (2006) observed that "if teachers do not pay attention to what motivates their pupils to learn, more students will fail both academically and socially”.

In the present era, it is mandatory for the secondary school science teachers must utilize approaches that fit their individual teaching styles”. Druger (2000) emphasized that by using these strategies a motivational learning environment in the classroom will be produced that will lead to positive attitudes and also increase the chance of students' 
achievement in their respective subjects (Druger, 2000). Moreover, the motivational classroom strategies increase the competition among secondary school students. Recently it has become common practice that both private and public schools in Pakistan are struggling for achieving positions in Board of Intermediate and Secondary Education (BISE) examinations. This kind of competition will compel the educational community to produce standardized, measurable results of students' achievement; therefore, secondary school science teachers are under increased pressure to motivate their students to perform better. This competitive environment is creating frustration among teachers of those students who expect to excel academically yet who are not willing to work for that success (Daniels \& Arapostathis, 2005; Mendler, 2000). Pickens (2007, p.12) noted that the educators must deal with students who do not want to work hard or who do not care for their future. According to Odera (2011, p.283) "motivation is one of the most important forces that guide students' actions. It involves a direction, a goal or an objective and the arousal of one or more drives. A successful science teacher needs to consider classroom motivational strategies that can be used to increase students' motivation and increase their active participation in learning”. One of the ways to motivate student is to use educational media and computer (Odera, 2011). The study by Carol (1997) supported the view of Odera (2011) that the utilization of computer technology in teaching and learning proved to be motivational activity.

Another motivational strategy used by the science teachers is the use of discrepant events as alternative strategy in inquiry based learning. In Pakistan, our most science teachers are generally not aware of new motivational strategies to teach the subject of science (Muhammad, 1998). Muhammad (1998) conducted a study at Agha Khan University, Karachi, Pakistan to confirm this view that "our science teachers are unaware to use discrepant events during science teaching" (p.1). The results of this revealed that "most science teachers place a heavy emphasis on rote learning, with students blindly following the procedures directed by the teacher. When student were introduced to the new strategy of discrepancy, they found themselves more confident to apply activities and practical work. There was a noticeable increase in student motivation, enthusiasm, and curiosity in the students' attitude towards science”. This study also indicated that both students and teachers realized that "the discrepant events strategy was beneficial to their students and 
showed their interest in using the approach in their class in the future”. Therefore it can be concluded that the use of discrepant events in science class was seen to significantly promote cognitive development of the students.

Mahmood, T., et al (2013, pp.563-570), compared teachers’ motivation as pedagogical technique between Public and Private Sector secondary schools in Pakistan. They noted that qualification and salary packages of government teachers were far better than that of private teachers, but the output was reverse. The researchers conducted a survey on a sample of 654 students from both public and private institutions to investigation about the use of motivational techniques in public and private institutions. It was found that teachers of both the sectors did not create intrinsic motivation among students. They also showed anger and punished students during teaching.

According to Nbina (2011, P.414), "Science is talk to the pupils using descriptive or lecture method instead of hands-on approach”. Effective science teachers must select particular teaching strategy to engage their students to develop their science concepts accurately to apply these concepts in their future studies. The present study intends to explore the teachers' conception towards the use of motivational classroom strategies to teach science subjects at secondary level in Pakistan.

\section{Objectives of Study}

The study intended to achieve the following objectives:

1. To indentify the types of motivational strategies used by science teachers.

2. To explore the significance difference between male and female science teachers in the use of motivational classroom strategies.

3. To examine the extent of the use of motivational classroom strategies by English medium and Urdu medium science teachers.

\section{Research Methodology}

A descriptive survey design that combined qualitative and quantitative methods was used. Questionnaire was the main instrument used for collection of data from the respondents.

\section{Population}


According to the Board of Intermediate and Secondary, Multan result gazette, 2013, there were 1098 secondary schools in the Multan Division. These comprised the population of the present study.

\section{Sample}

The sample consisted of two districts of Multan division; Multan and Vehari. All schools (517) of these two districts, (in Multan 306 schools and in Vehari 211schools) were the target population. 51 schools were selected randomly by using the table of random numbers. 256 teachers from the sample schools completed the research questionnaire.

\section{Tool of Research:}

The data collection instrument was a questionnaire consisting of 25 closed ended test items developed on five point Likert type scales.

\section{Data Analysis}

The collected data was organized and tabulated by using the spread sheet by using MS-Excel and analyzed by using the Statistical Package for Social Sciences (SPSS) and Minitab software to arrive at some conclusions. The software was used to calculate frequencies, percentages, mean score to see the agreement of respondents on the statements while t-test was applied to see the significant difference between different variables of research. Weighted means for the responses were also computed.

\section{Results}

From the data analysed, findings and conclusions drawn are given below:

Table 1

Analysis of Attitude Scale $\quad \mathrm{N}=\mathbf{2 5 6}$

\begin{tabular}{|c|c|c|c|c|c|c|c|}
\hline $\begin{array}{l}\text { Sr. } \\
\text { no }\end{array}$ & Statements & SA & A & $\mathbf{U}$ & D & SD & $\begin{array}{l}\text { Weighted } \\
\text { mean }\end{array}$ \\
\hline \multirow[t]{2}{*}{1} & \multirow{2}{*}{$\begin{array}{l}\text { I use A.V aids as strategy to improve } \\
\text { teaching learning process }\end{array}$} & 65 & 61 & 53 & 53 & 24 & \multirow[t]{2}{*}{3.35} \\
\hline & & $25 \%$ & $23 \%$ & $20 \%$ & $20 \%$ & $9.4 \%$ & \\
\hline \multirow[t]{2}{*}{2} & \multirow{2}{*}{$\begin{array}{l}\text { I encourage my students to work in } \\
\text { small groups }\end{array}$} & 75 & 65 & 44 & 42 & 30 & \multirow[t]{2}{*}{3.44} \\
\hline & & $29 \%$ & $25 \%$ & $17 \%$ & $17 \%$ & 12 & \\
\hline \multirow[t]{2}{*}{3} & \multirow{2}{*}{$\begin{array}{l}\text { I arrange innovative activities to teach } \\
\text { science in the class }\end{array}$} & 64 & 65 & 37 & 68 & 21 & \multirow[t]{2}{*}{3.31} \\
\hline & & $25 \%$ & $26 \%$ & $15 \%$ & $26 \%$ & $8 \%$ & \\
\hline \multirow[t]{2}{*}{4} & \multirow{2}{*}{$\begin{array}{l}\text { I try to promote competition spirit } \\
\text { among students }\end{array}$} & 67 & 38 & 48 & 71 & 32 & \multirow[t]{2}{*}{3.1} \\
\hline & & $26 \%$ & $15 \%$ & $19 \%$ & $27 \%$ & $13 \%$ & \\
\hline 5 & I monitor students' best work and & 47 & 74 & 66 & 41 & 28 & 3.27 \\
\hline
\end{tabular}




\begin{tabular}{|c|c|c|c|c|c|c|c|}
\hline & $\begin{array}{l}\text { celebrate it in class to motivate other } \\
\text { students }\end{array}$ & $18 \%$ & $29 \%$ & $26 \%$ & $16 \%$ & $11 \%$ & \\
\hline \multirow[t]{2}{*}{6} & \multirow{2}{*}{$\begin{array}{l}\text { I encourage students to fix specific } \\
\text { goals to achieve targets }\end{array}$} & 49 & 68 & 63 & 38 & 38 & \multirow[t]{2}{*}{3.20} \\
\hline & & $19 \%$ & $27 \%$ & $24 \%$ & $15 \%$ & $15 \%$ & \\
\hline \multirow[t]{2}{*}{7} & \multirow{2}{*}{$\begin{array}{l}\text { I try to establish good relations with } \\
\text { students }\end{array}$} & 55 & 64 & 67 & 42 & 28 & \multirow[t]{2}{*}{3.29} \\
\hline & & $22 \%$ & $25 \%$ & $26 \%$ & $16 \%$ & $11 \%$ & \\
\hline \multirow[t]{2}{*}{8} & \multirow{2}{*}{$\begin{array}{l}\text { I encourage group discussion in the } \\
\text { classroom }\end{array}$} & 65 & 61 & 53 & 53 & 24 & \multirow[t]{2}{*}{3.35} \\
\hline & & $25 \%$ & $24 \%$ & $21 \%$ & $21 \%$ & $9 \%$ & \\
\hline \multirow[t]{2}{*}{9} & \multirow{2}{*}{$\begin{array}{l}\text { I try to start my lesson with some } \\
\text { activity }\end{array}$} & 75 & 65 & 44 & 42 & 30 & \multirow[t]{2}{*}{3.4} \\
\hline & & $29 \%$ & $26 \mathrm{~s} \%$ & $17 \%$ & $16 \%$ & $12 \%$ & \\
\hline \multirow[t]{2}{*}{10} & \multirow{2}{*}{$\begin{array}{l}\text { I display the names of successful } \\
\text { students in classroom }\end{array}$} & 75 & 65 & 44 & 42 & 30 & \multirow[t]{2}{*}{3.4} \\
\hline & & $29 \%$ & $26 \mathrm{~s} \%$ & $17 \%$ & $16 \%$ & $12 \%$ & \\
\hline \multirow[t]{2}{*}{11} & \multirow{2}{*}{$\begin{array}{l}\text { I take notice of students' contributions } \\
\text { and progress, and provide them with } \\
\text { positive feedback. }\end{array}$} & 64 & 66 & 37 & 68 & 21 & \multirow[t]{2}{*}{3.32} \\
\hline & & $25 \%$ & $26 \%$ & $15 \%$ & $26 \%$ & $8 \%$ & \\
\hline \multirow[t]{2}{*}{12} & \multirow{2}{*}{$\begin{array}{l}\text { I use demonstration method to teach } \\
\text { science lessons }\end{array}$} & 67 & 38 & 48 & 71 & 32 & \multirow[t]{2}{*}{3.14} \\
\hline & & $26 \%$ & $15 \%$ & $19 \%$ & $28 \%$ & $12 \%$ & \\
\hline \multirow[t]{2}{*}{13} & \multirow{2}{*}{$\begin{array}{l}\text { I Show students that their effort are } \\
\text { being recognized by me }\end{array}$} & 67 & 38 & 48 & 71 & 32 & \multirow[t]{2}{*}{3.14} \\
\hline & & $26 \%$ & $15 \%$ & $19 \%$ & $28 \%$ & $12 \%$ & \\
\hline \multirow[t]{2}{*}{14} & I give opportunities to the students to & 47 & 74 & 66 & 41 & 28 & 3.27 \\
\hline & assess themselves & $18 \%$ & $29 \%$ & $26 \%$ & $16 \%$ & $11 \%$ & \\
\hline 15 & I encourage students to share personal & 49 & 68 & 63 & 38 & 38 & 3.20 \\
\hline & experiences in the class & $19 \%$ & $26 \%$ & $25 \%$ & $15 \%$ & $15 \%$ & \\
\hline 16 & I give awards to my students on best & 55 & 64 & 67 & 42 & 28 & 3.29 \\
\hline & performance & $22 \%$ & $25 \%$ & $26 \%$ & $17 \%$ & $10 \%$ & \\
\hline 17 & I use variety of teaching methods in the & 55 & 64 & 67 & 42 & 28 & 3.29 \\
\hline & class & $22 \%$ & $25 \%$ & $26 \%$ & $17 \%$ & $10 \%$ & \\
\hline 18 & I use computer technology while & 65 & 51 & 53 & 53 & 24 & 3.19 \\
\hline & teaching & $25 \%$ & $24 \%$ & $21 \%$ & $21 \%$ & $09 \%$ & \\
\hline 19 & I encourage students’ participation by & 75 & 65 & 44 & 42 & 30 & 3.41 \\
\hline & assigning activities & $29 \%$ & $26 \%$ & $17 \%$ & $16 \%$ & $12 \%$ & \\
\hline 20 & I provide learning environment to my & 75 & 66 & 43 & 42 & 30 & 3.44 \\
\hline & science students & $29 \%$ & $26 \%$ & $17 \%$ & $16 \%$ & $12 \%$ & \\
\hline 21 & I use science laboratory to make my & 64 & 66 & 37 & 68 & 21 & 3.32 \\
\hline & lesson, a success & $25 \%$ & $26 \%$ & $15 \%$ & $26 \%$ & $8 \%$ & \\
\hline 22 & I always use brainstorming activities to & 68 & 38 & 47 & 71 & 32 & 3.15 \\
\hline & stimulate creative thinking & $27 \%$ & $15 \%$ & $18 \%$ & $28 \%$ & $12 \%$ & \\
\hline 23 & I support my instruction by creating & 67 & 38 & 46 & 71 & 32 & 3.12 \\
\hline & humour during lesson & $26 \%$ & $15 \%$ & $19 \%$ & $28 \%$ & $12 \%$ & \\
\hline 24 & I try to get my students actively & 47 & 74 & 66 & 41 & 28 & 3.27 \\
\hline & involved in class & $18 \%$ & $29 \%$ & $26 \%$ & $16 \%$ & $11 \%$ & \\
\hline 25 & I my lesson, i make use of examples & 65 & 61 & 53 & 53 & 24 & 3.35 \\
\hline & from the real world & $25 \%$ & $24 \%$ & $21 \%$ & $21 \%$ & $09 \%$ & \\
\hline
\end{tabular}


Table 1 indicates that the mean score of all the statements ranges from 3.12 to 3.44 , which shows the higher agreement of all the respondents on all the statements given in the questionnaire. It means all the respondents agreed on the use of motivational classroom strategies to motivate their students to help them to learn science effectively which provide base to cope with higher level science in future.

Table 2

Mean, Standard Deviation and $t$ - value for the score of male teachers $(n=143)$ and female teachers $(n=113)$ on the scale of Motivational Classroom Strategies.

\begin{tabular}{lllllll}
\hline Variable & Gender & $n$ & $M$ & $S D$ & $T$ & $P$
\end{tabular}

\begin{tabular}{lllll}
\hline Motivational & Male & 143 & 94.6 & 13.7
\end{tabular}

Classroom Strategies

$143-13.7$

$$
13.65 \quad 0.000 * * *
$$

Female $\quad 113 \quad 70.2 \quad 14.8$

$(d f=254, * * * p<.001)$

The table 2 shows the results for the scores of Motivational Classroom Strategies for the male teachers and female teachers. The results showed that the level of using Motivational Classroom Strategies was significantly higher in male teachers as compared to female teachers. $(d f=254, t=13.65, p=0.000)$.

\section{Table 3}

Mean, Standard Deviation and t-value for the score of teachers whose medium of teaching is in English (n=99) and teachers whose medium of instruction is in Urdu $(n=167)$ on the scale of Motivational Classroom Strategies.

\begin{tabular}{|c|c|c|c|c|c|c|}
\hline Variable & Version & $n$ & $M$ & $S D$ & $t$ & $P$ \\
\hline Motivational & English & 99 & 102.8 & 9.07 & & \\
\hline \multicolumn{6}{|c|}{ Classroom Strategies } & $0.000 * * *$ \\
\hline & Urdu & 167 & 71.8 & 12.0 & & \\
\hline
\end{tabular}

$(d f=254, * * * p<.001)$ 
Table 3 shows the results for the scores of Motivational Classroom Strategies for the English version teachers and Urdu version teachers. The results showed that the level of using Motivational Classroom Strategies was significantly higher in English medium teachers as compared to Urdu medium teachers ( $d f=254, t=22.08, p=0.000)$.

\section{Discussion}

Motivational strategies are important to teach science students in an effective way to enhance their interest to learn concepts of science with full zeal. It is all depending upon science teachers of secondary school that how they utilize their skills to motivate their students by using motivational strategies in their classrooms. The findings of the study showed that all the respondents have given the positive responses on the use of motivational classroom strategies used by the secondary school science teachers to motivate their students to help them to learn science effectively which provide base to cope with higher level science in future. Furthermore, in comparison of the male teachers and female teachers to use motivational classroom strategies, the results showed that the level of using Motivational Classroom Strategies was significantly higher in male teachers as compared to female teachers. Similarly, Motivational Classroom Strategies used by English medium teachers and Urdu medium teachers, the results showed that the level of using Motivational Classroom Strategies was significantly higher in English medium teachers as compared to Urdu medium teachers.

Research studies conducted Picken (2007), Theobald (2006) and Muhammad (1998), showed that teachers of both the sectors did not create intrinsic motivation among students. Findings of this study also revealed that teachers did not present models as a helping material which was a good academic technique for student motivation for learning.

\section{Conclusions}

The following conclusions were drawn from the findings of the present study: 
1. Majority of the science teachers use A.V aids as motivational strategy to improve teaching learning process in their classrooms to enhance teaching learning process.

2. Most of the science teachers were in favor to encourage their students to work in small groups to help each other to cooperate in learning science.

3. Secondary school science teacher agreed that they arrange innovative activities to teach science in their classrooms.

4. Many science teachers tried to promote competition spirit among their students to enhance students’ interest towards their learning task.

\section{Recommendations}

1. This study may indicate that teachers can play an important role in strengthening the concept of their students by using different classroom motivational strategies.

2. If proper guidance and motivation be provided to the science students their educational attainments can be improved.

3. Science teachers should use both intrinsic and extrinsic motivational strategies to attain maximum results.

\section{REFERENCES}

Atta, M. A. and Jamil, A. (2012), Effects of motivation and parental influence on the educational attainments of students at secondary level, Academic Research International, Vol.2, No. 3, May 2012, pp. 427-431.

arol, G. (1997). IT in the West Midlands. Facts and views. Language Learning Journal. March. No. 15, 52-59.

Druger, M. (2000). Creating a motivational learning environment in science: Adding a personal touch to the large lecture. Journal of college science teaching. 30, 222-224.

Evans, C. (2004). Learning with inquiring minds. The Science Teacher. 71, 27-30.

Mahmood, T., Ahmed, M., Shoaib, H., and Ghuman, M. A. (2013) 'Motivation as Pedagogical Technique for Teachers: A Cross Comparison Between Public and Private Sector', Mediterranean Journal of Social Sciences(Published by MCSER-CEMAS- 
Sapienza University of Rome), Vol 4 No 2, May 2013, pp. 563-70; ISSN 2039-2117 (online)ISSN 2039-9340 (print)

Muhammad, S. (1998). The use of discrepant events as an alternative science teaching strategy in lower secondary classrooms (Unpublished master's dissertation). Aga Khan University, Karachi, Pakistan.

Mary, A. (2010). Motivation and the Performance of Primary School Teachers in Uganda: A Case of Kimaanya-Kyabakuza Division, Masaka District. Unpulished thesis submitted for the M.A degree at Makerere University

Nbina, J. B. (2011). Revisiting secondary school science teachers' motivation strategies to face the challenges of the 21st century. Journal of Emerging Trends in Educational Research and Policy Studies (JETERAPS), 2(6), 413-417.

Odera, F. Y. (2011). Motivation: the most Ignored Factor in Classroom Instruction in Kenyan Secondary Schools. International Journal of Science and Technology, 1(6). Retrieved from http://ejournalofsciences.org/archive/vol1no6/vol1no6_15.pdf

Pickens, M. (2007). Teacher and Student Perspectives on Motivation Within the High School Science Classroom. Retrieved from http://etd.auburn.edu/etd/handle/10415/34

Mellado, V., Bermejo, M. A., blanco, L. J., \& Ruiz, C., (2007). The Classroom Practice of a Prospective Secondary Biology Teacher and his Conceptions of the Nature of Science and of Teaching and Learning Science. Retrieved from www.eweb.unex.es/eweb/dcem/ar08ijsme.pdf accessed on December 14, 2013. 